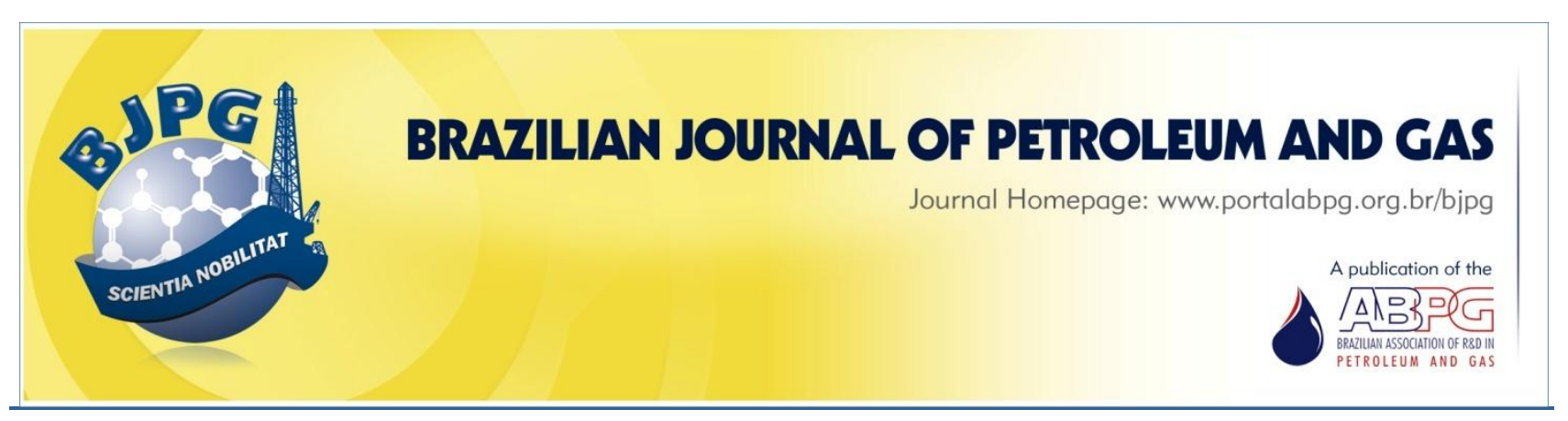

\title{
ANALYSIS OF THE INCLINATION INFLUENCE IN A COALESCER COLUMN FOR OIL/WATER TREATMENT VIA COMPUTATIONAL FLUID DYNAMICS
}

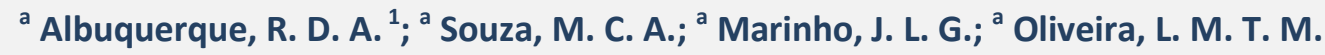 \\ ${ }^{a}$ Federal University of Alagoas, Petroleum Engineering Program, Maceió - AL - Brazil
}

Received: 04.11.2019 / Revised: 05.03.2020 / Accepted: 16.03.2020 / Published on line: 06.05.2020

\begin{abstract}
Among the equipments used in the separation of water from oil, bed coalescers stands out. Even after decades of bed coalescer development, the role of some variables, such as apparatus inclination, in its behavior remains underexplored within the field. Thus, using the ANSYS CFX 13.0 software, a modeling was proposed to determine the influence of bed coalescer inclination in the separation rate of oil from produced water. The software analyzes four inclinations relative to the horizontal axis $\left(0^{\circ}, 15^{\circ}, 30^{\circ}\right.$ and $\left.60^{\circ}\right)$. The results from simulations identified oil accumulating zones and presence of recirculation zones. It also compared the pressure drop throughout the apparatus in all inclinations established, noting that a more favorable state occurs when the bed is at horizontal, presenting higher oil accumulation, fewer vorticity, and lower pressure drop. The less desirable scenario occurs with $60^{\circ}$ inclination, displaying a lower separation efficiency, greater pressure drop, and higher turbulence effect.
\end{abstract}

\section{KEYWORDS}

ANSYS CFX; bed coalescer; CFD; deep bed filtration; produced water

\footnotetext{
${ }^{1}$ To whom all correspondence should be addressed.

Address: Federal University of Alagoas, Petroleum Engineering Program, Av. Lourival Melo Mota, s/n, Maceió - AL - Brazil. Zip Code: 57072-900 | Phone number: +55(82) 3214-1292 | e-mail: $\underline{\text { raniel.albuquerque@ctec.ufal.br }}$ doi:10.5419/bjpg2020-0003
} 


\section{INTRODUCTION}

Oil price is conditioned by several factors, making it necessary, in periods of devaluation, to reduce production costs to enable trade for this product. Thus, the oil industry is constantly seeking to reduce the main expenses linked to oil production, and, among these, is the treatment of oil produced water (PW).

Produced water is a byproduct generated in the petroleum extraction, being the main effluent originated in the productive chain (Amini et al., 2012). The industry estimates that for each barrel of extracted oil about three barrels of produced water are obtained (Arowoshola et al., 2011). The PW has a complex composition, consisting of salts, solids, and oil (Igunnu et al., 2014). Such peculiarity makes PW treatment a complex process, generating concern for producing companies. These companies have the duty to carry out an adequate treatment of this product for its future disposal, either by reinjecting the produced water or launching it at sea (Ariaratnam \& Roth, 2016).

The daily rate allowed for releasing oil at sea varies by each country. Brazil limits this release to $20 \mathrm{mg}$ per liter of water (Brazil, 2011). Thus, the reduction of costs can be achieved by optimizing the treatment of this water, either by developing of new mechanisms or improving the equipment already in place.

Therefore, among the equipment used in the separation of water from oil, the bed coalescer appears as an alternative. The equipment is composed by a column for separating liquid-liquid dispersions above the solubility limit (Speth et al., 2002). In this equipment, the dispersion is pumped through a bed of porous material so that tortuosity and increased saturation of the system promote the collision and coalescence of the droplets of the dispersed fluid. Larger droplets are drawn out of the porous medium by dynamic forces leading to more efficient gravitational separation downstream of the pores (Speth et al., 2002; Sokolovic et al., 2009; Kulkarni et al., 2012) and, hence, promoting the purification of the continuous phase.

The optimization of bed coalescers is a challenge. Since its first use, dated to 1908, (Sherony \& Kintner, 1971) no mathematical model to relate the large number of variables involved in the process has been developed (Sokolovic et al, 2007). Aspects that need attention include the geometry of equipment, bed properties, as well as other variables not analyzed in studies, such as the slope of the apparatus.

Sherony and Kintner's study (1971) describes the history of bed coalescers up to the 1970s, with the first patent dating from 1908 and the subsequent popularization of this equipment in the 1930s. However, the authors emphasize that, up to that moment, published works describing coalescing columns were scarce. Magiera and Blass (1997) pointed out the difficulty in predicting the operation of bed coalescers due to the alteration of some parameters, such as the material that constitutes the bed.

Sokolovic et al. (2016) carried out a state-ofthe-art study pointing out several advances in the understanding of the phenomena that govern the operation of bed coalescers. However, when dealing with the influence of inclination in the apparatus operation, the authors only dealt with the cases in which the equipment is arranged horizontally and vertically. On a different note, Vigneaux et al. (1988) analyzed the flow of fluids inside a duct under different inclinations. Thus, there is a lack of studies that specifically describe the behavior of bed coalescers under different slopes.

The analysis of bed coalescers can then be performed using computational fluid dynamics (CFD), which has been used increasingly to solve complex engineering problems involving fluids. Based on the use of conservative laws, this approach allows the attainment of reliable results at a low cost in relation to experimental studies, as well as simplified parameter variation and easier observation of results (Hirsch, 2007).

Therefore, the present work proposes to simulate a coalescer column, and to analyze the influence of inclination in relation to the horizontal axis in the operation of the bed coalescers. The observations were made from areas of oil accumulation, streamlines, and pressure drop along the equipment for four slopes in relation to the horizontal axis. Based on the observations, we determined which of the configurations presented better efficiency. At last, results were compared to those found in literature. 


\section{METHODOLOGY}

For modeling the separation phenomenon, the procedure was divided in three parts: Numerical meshes generation, corresponding to the geometric model of the coalescer bed and fluids system; mathematical development; and physical characterization of the system with the application of initial and boundary conditions

\subsection{Mesh generation}

Four numerical meshes were generated with slopes $(\alpha)$ in relation to the horizontal axis $-0^{\circ}, 15^{\circ}$, $30^{\circ}$, and $60^{\circ}$ - so that each numerical mesh had approximately 151,000 elements and 27,000 nodes. The definition of the element's density was conditioned to the need for greater detail in certain areas such as entrance, outlet, and interfacial zones.

In Figure 1, regions 1 (inlet) and 5 (outlet) present the density of elements four times greater than the others. The model consists of two domains, one porous (region 3) and another fluid (remainder of the equipment). The dimensions of
Table 1. Apparatus dimensions.

\begin{tabular}{lccc}
\hline \multicolumn{1}{c}{ Region } & $\begin{array}{c}\text { Notation } \\
\text { (Figure 1) }\end{array}$ & $\begin{array}{c}\text { Diameter } \\
\text { (cm) }\end{array}$ & $\begin{array}{c}\text { Length } \\
\text { (cm) }\end{array}$ \\
\hline Inlet & 1 & 0.635 & 2 \\
Initial pipe & 2 & 10 & 10 \\
Porous bed & 3 & 10 & 10 \\
Pipe end & 4 & 10 & 65 \\
Outlet & 5 & 0.635 & 10 (quota) \\
\hline
\end{tabular}

the apparatus were set as shown in Table 1.

\subsection{Mathematical modeling}

A model based on the work developed by Ferreira et al. (2018) was used to carry out the study, using the ANSYS CFX 13.0, a CFD application, which is governed by transport equations that use the principles of mass and momentum conservation. The following considerations for the model were made: 1) Isothermal and
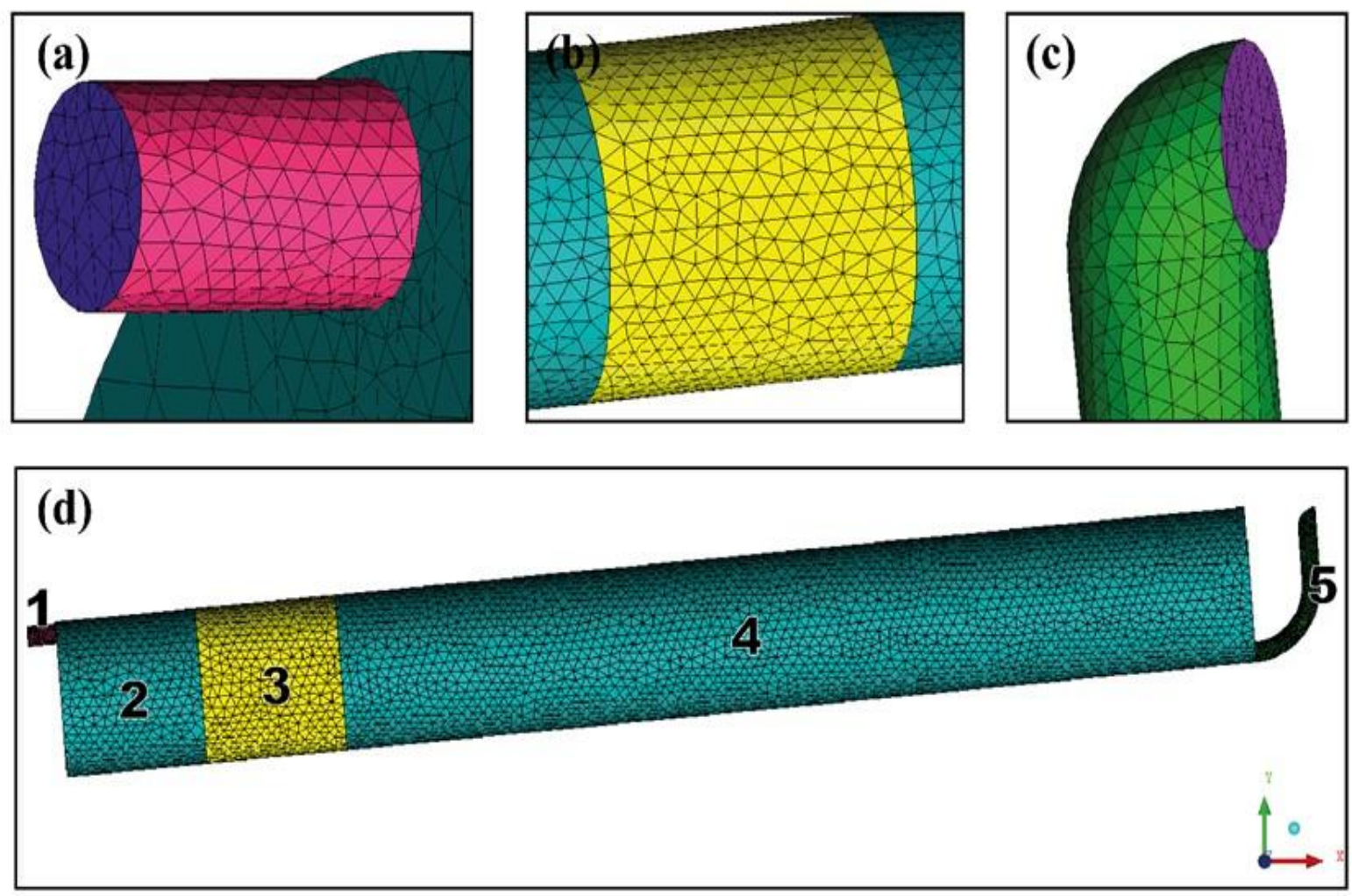

Figure 1. Numerical mesh details for $\alpha=5^{\circ}$, showing the equipment parts: (a) inlet, (b) porous bed, (c) outlet, and (d) whole apparatus. 
incompressible flow; 2) Transient state; 3) Gravitational effects; 4) Three-dimensional domain; 5) Properties of the constant fluids; 6 ) There are no chemical reactions; 7) Turbulence governed by the $\mathrm{k}-\varepsilon$ model.

For the modeling, a Eulerian-Eulerian approach was used, adopting a particle model so that the oil was considered the dispersed phase. The IshiiZuber (Ishii \& Zuber, 1979) model was used to represent the drag effect on the particles.

\subsubsection{Fluid domain equations}

To describe mass conservation in the fluid domain, Equation 1 was used, where $\frac{\partial \rho}{\partial t}$ represents the mass variation with time, $\nabla .(\rho \mathbf{U})$ the input and output flows in the control volume, $\rho$ the density of the fluid and $\mathbf{U}$ is the flow velocity vector (ANSYS, 2010).

$\frac{\partial \rho}{\partial t}+\nabla \cdot(\rho \mathbf{U})=0$

The conservation of momentum is described by Equation 2, which encompasses the forces acting on the flow, being $\nabla p$ the pressure gradient, $\tau$ the stress tensor, and $S_{M}$ the moment source, which synthesizes some forces acting on the fluid, such as thrust and drag coefficient.

$$
\frac{\partial(\rho \mathbf{U})}{\partial t}+\nabla \cdot(\rho \mathbf{U} \otimes \mathbf{U})=-\nabla p+\nabla \cdot \tau+S_{M}
$$

\subsubsection{Porous domain equations}

For the discretization of the porous domain, a correlation between the Navier-Stokes equations and the Darcy's Law was used, resulting in the mass conservation equation (Equation 3), where $\gamma$ represents the porosity in the domain and $\mathbf{K}$ the permeability of the porous medium, and the momentum conservation equation (Equation 4).

$$
\begin{aligned}
& \frac{\partial}{\partial t}(\gamma \rho)+\nabla \cdot(\rho \mathbf{K} \cdot \mathbf{U})=0 \\
& \frac{\partial(\gamma \rho \mathbf{U})}{\partial t}+\nabla \cdot(\rho(\mathbf{K} \cdot \mathbf{U}) \otimes \mathbf{U})- \\
& -\nabla\left(\mu_{e} \mathbf{K}\left(\nabla \mathbf{U}+(\nabla \mathbf{U})^{T}-\frac{2}{3} \delta \nabla \cdot \mathbf{U}\right)\right)= \\
& =-\gamma \nabla p+\gamma S_{M}
\end{aligned}
$$

\subsubsection{Coalescence model}

The model of Prince and Blanch (1990) was used to represent the phenomenon of coalescence. This model idealizes that coalescence occurs in three steps: initially two bubbles $\left(m_{i}\right.$ e $\left.m_{j}\right)$ collide and, when this occurs, they form a thin film of liquid. Along the time, the thickness of the film is reduced, forming a small film that, if ruptured, causes the bubbles to merge (ANSYS, 2010). Such behavior is described by Equation 5 .

$Q\left(m_{i} ; m_{j}\right)=\left(\theta_{i j}^{T}+\theta_{i j}^{B}+\theta_{i j}^{S}\right) e^{-t_{i j} / \tau_{i j}}$

Where $t_{i j}$ is the time required to coalescence, $\tau_{i j}$ is the actual contact time between the bubbles, and $\theta_{i j}^{T}, \theta_{i j}^{B}, \theta_{i j}^{S}$, are the collision frequencies between the bubbles, these being, respectively, the frequency of interactions generated by turbulent velocity fluctuation, frequency generated by thrust and frequency of collisions due to laminar shear (Prince \& Blanch, 1990).

\subsection{Boundary conditions and fluids' properties}

The production water is composed of two phases: one of them continuous, the water, and the other dispersed, the oil. To model the oil, a complex mixture, it was used a group of 5 (five) average particle diameters, ranging from 18-23 $\mu \mathrm{m}$ distributed randomly along the system. For the physical characterization of the water, the model was used in the ANSYS CFX 13.0 library, with a density of $997 \mathrm{~kg} / \mathrm{m}^{3}$ at $25{ }^{\circ} \mathrm{C}$. For the characterization of the oil and bed, we used the properties set found in Tables 2 and 3, respectively.

The mixture, representing the produced water, was injected into the bed at a rate of $60 \mathrm{~L} / \mathrm{h}$ with an oil concentration of $1500 \mathrm{ppm}$. The simulations

Table 2. Oil properties.

\begin{tabular}{lc}
\hline Density & $844.73 \mathrm{~kg} / \mathrm{m}^{3}$ \\
\hline Mean molecular mass & $349 \mathrm{~g} / \mathrm{mol}$ \\
\hline Viscosity & $21.73 \mathrm{mPa} . \mathrm{s}$ \\
\hline Interfacial tension & $18.04 \mathrm{mN} / \mathrm{m}$ \\
\hline Source: Sokolovic et al. (2003).
\end{tabular}

Source: Sokolovic et al. (2003). 
Table 3. Bed properties.

\begin{tabular}{lc}
\hline Porosity & $96 \%$ \\
\hline Permeability & $0.0055 \mathrm{~mm}^{2}$ \\
\hline
\end{tabular}

Source: Sokolovic et al. (2003).

were performed in the transient regime, testing the coalescing bed for one hour of operation, with 10 -second time steps and tolerance of $10^{-6}$ for RMS (Root Mean Square) error.

\section{RESULTS AND DISCUSSION}

The behavior described by Albuquerque et al. (2018) in their study was observed for all simulation cases, varying only the intensity of the separation. The fluid inserted through the equipment inlet flowed towards the porous bed. Then, the dispersed oil droplets collided with the bed's fibers and grouped together forming droplets with a larger diameter, undergoing the action of thrust and grouping at the top of the equipment. Other experimental authors had observed the same behavior (Sokolovic et al., 2009; Sokolovic et al., 2007). With this, the influence of the inclination in the operation of bed coalescers could be analyzed, being the analysis divided in the study of the regions of accumulation of oil, behavior of the streamlines, and pressure drop in the apparatus.

\subsection{0il concentration analysis}

Figure 2 shows the results for the simulations with $\alpha=0^{\circ}, 15^{\circ}, 30^{\circ}$, and $60^{\circ}$, respectively. These four cases demonstrate the behavior of the

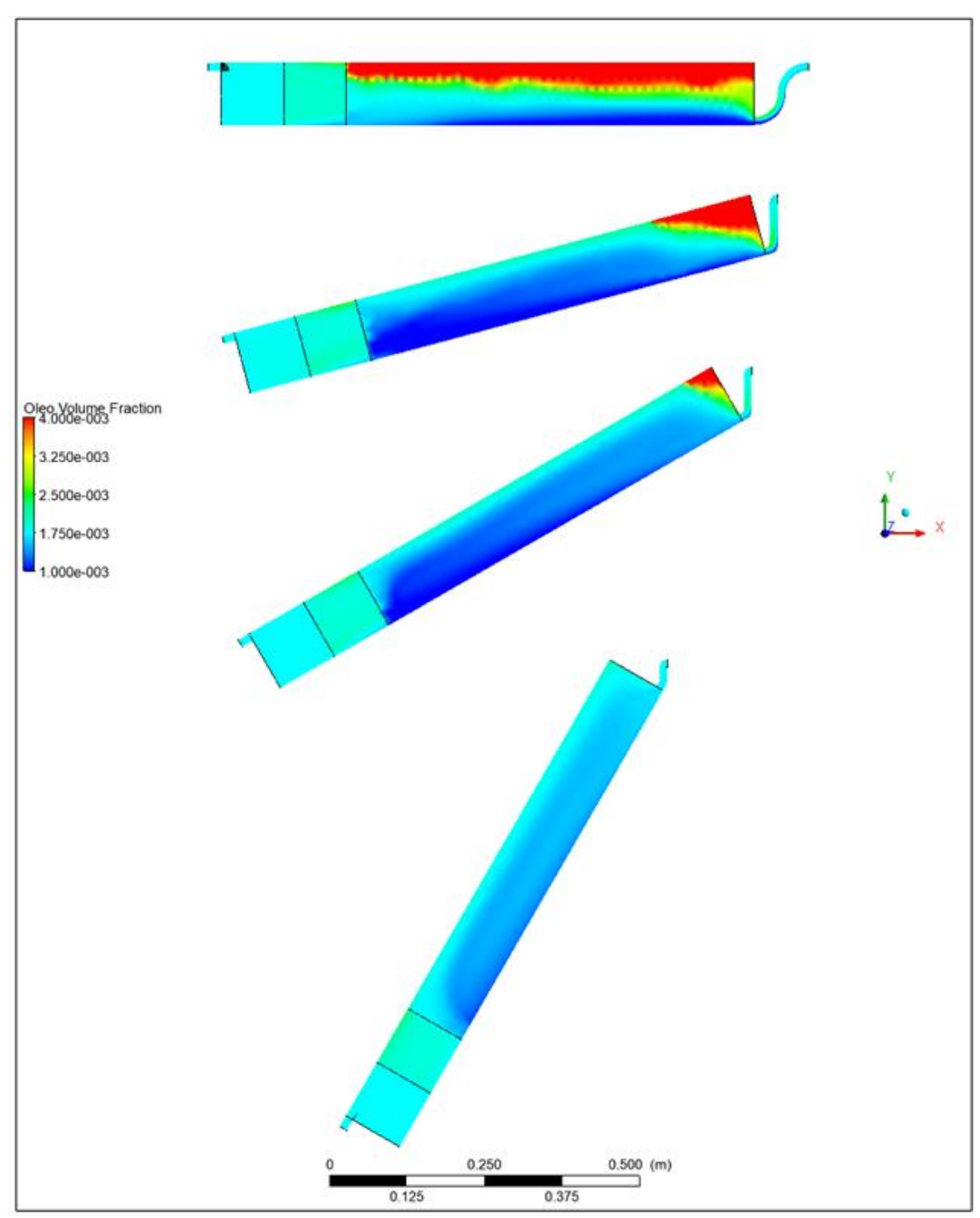

Figure 2. Change-over the oil concentration along the apparatus for the configurations with $\alpha=0^{\circ}(a), \alpha=15^{\circ}$ (b), $\alpha=30^{\circ}$ (c), and $\alpha=60^{\circ}$, revealing the tendency to decrease the rate of separation of oil with the increase of the slope. 
variation of oil concentration with the increase of the bed coalescer's inclination. One can verify that the higher the slope is, the more difficult the removal becomes. This happens because the oil particles are subjected to a shorter residence time inside the porous bed due to the buoyancy suffered by the oil, causing fewer collisions between them and lowering coalescence rate. Sokolovic et al. (2016) pointed out that, observed experimentally with increasing inclination, the hydrodynamic forces tend to force the droplets out of the bed, reducing the contact time between oil droplets and, consequently, the coalescence rate.

The best result was obtained at $\alpha=0^{\circ}$, without the gravity influence. This result obtained the best separation rate, which is evidenced by the higher saturation at the top of the apparatus (the particles go to the top of the duct faster). In addition, this configuration would favor the removal of oil, later, through the implementation of an outlet in the upper region.

For $\alpha=15^{\circ}$ there is a visible reduction in oil concentration at the top of the coalescer. This

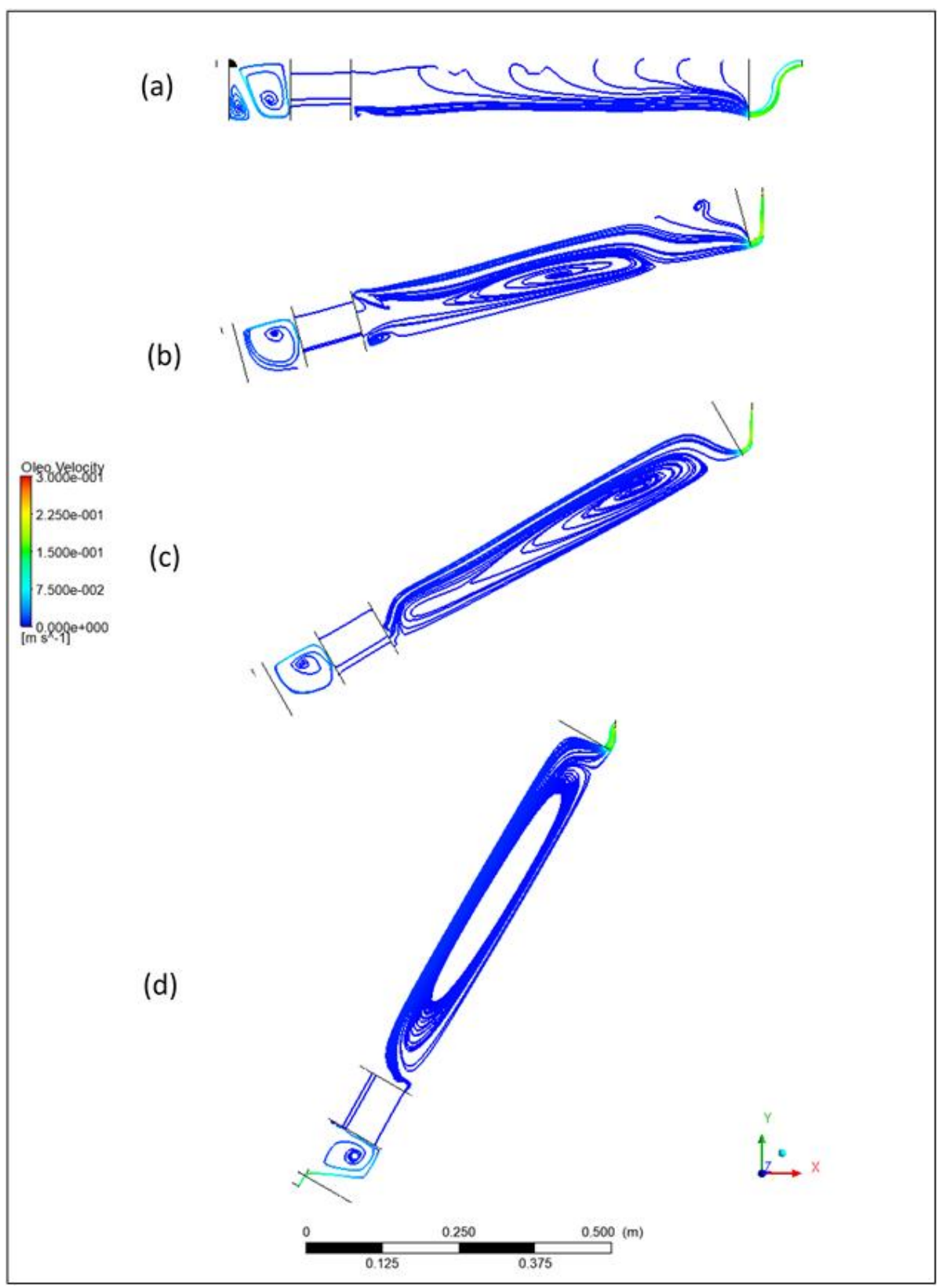

Figure 3. Streamlines with $\alpha=0^{\circ}(\mathrm{a}), \alpha=15^{\circ}(\mathrm{b}), \alpha=30^{\circ}(\mathrm{c})$, and $\alpha=60^{\circ}(\mathrm{d})$, evidencing the recirculation zone increases with increasing inclination of the apparatus. 
smaller accumulation of oil occurs because, due to the geometry of the apparatus, the area that holds the oil is small, favoring its escape.

In the case where $\alpha=30^{\circ}$ there is still a region with a high concentration of oil, although this is smaller than in the previous cases, so that the coalescer geometry is no longer the limiting agent for oil accumulation. The less favorable situation occurred when $\alpha=60^{\circ}$. Having a lower separation rate, the oil concentration was qualitatively lower than those observed in the other cases.

The increase of oil dispersion with the increase of the inclination is in accordance with the behavior observed by Vigneaux et al. (1988). In their study of flow inside inclined ducts, they conclude that even from small increments in the inclination, oil distribution in the cross-section of the flow presents great variations. Also, in inclinations with the horizontal below $30^{\circ}$ a greater concentration of oil is observed, forming continuous regions in the upper zone.

\subsection{Analysis of streamlines}

In Figure 3 , there is a comparison between system velocity streamlines for $\alpha=0^{\circ}, 15^{\circ}, 30^{\circ}$, and

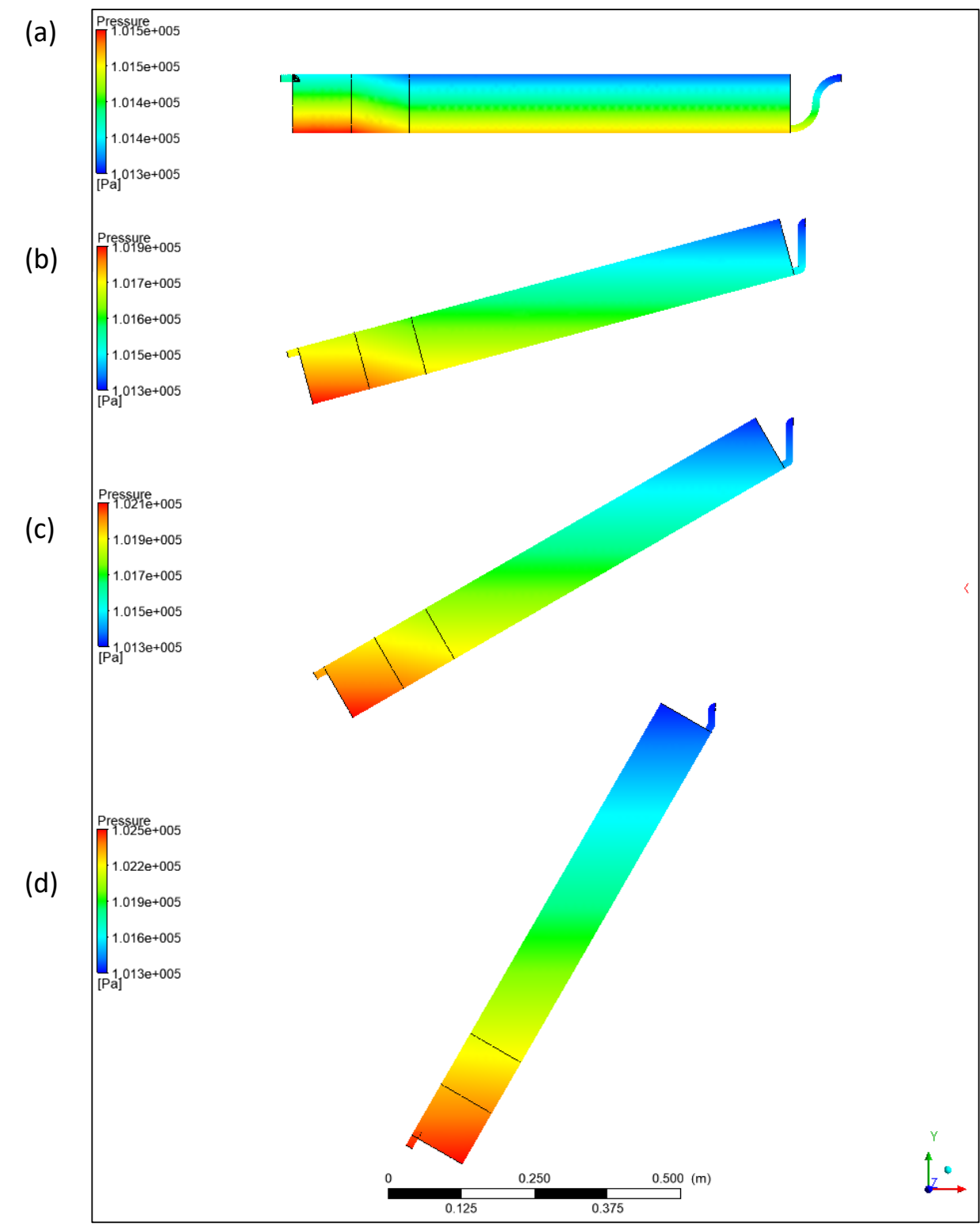

Figure 4. Pressure drop across the apparatus with $\alpha=0^{\circ}(\mathrm{a}), \alpha=15^{\circ}$ (b), $\alpha=30^{\circ}$ (c), and $\alpha=60^{\circ}$ (d), showing the pressure drop increment with increase of the slope. 
$60^{\circ}$. One can observe that, when the coalescer is at a horizontal position, there is the smallest number of recirculation zones after the porous bed in comparison to the other configurations. The lines show oil particles flowing to the upper region of the apparatus and a laminar behavior of the system to follow until the lower pressure region (outlet).

When $\alpha=15^{\circ}$, a visible reduction in the number of streamlines flowing to the top of the apparatus is observed. In addition, the presence of a recirculation zone in the center of the equipment can be noted. However, when increasing the inclination of the apparatus to $\alpha=30^{\circ}$, no more streamlines flow into the region with the highest concentration of oil, evidencing that this configuration reached its maximum oil concentration. Also, an increase of intensity in the recirculation region is noticed. Finally, for $\alpha=60^{\circ}$, a new increase in the system's turbulence is observed, generating a large recirculation zone covering the whole region after the bed.

As the inclination of the apparatus increases, the presence of recirculation zones tends to rise. The oil phase, which has a higher velocity now for buoyancy influence, when dragged fast for the upper region of the apparatus, generate a lowpressure zone in the center, causing the vortex. This behavior is consistent with that of fluid flow in inclined beds (Vigneaux et al., 1988). In addition, the recirculation zones are undesirable because they denote the presence of turbulence, since it favors the stability of the emulsions (Maiti et al., 2011), which explains the decrease tendency in the rate of oil separation with the inclination increase.

\subsection{Pressure drop analysis}

An analysis of the pressure drop across the apparatus in Figure 4, which compares cases where $\alpha=0^{\circ}, 15^{\circ}, 30^{\circ}$, and $60^{\circ}$, shows that, due to the weight exerted by the fluid, the pressure drop tends to increase with the increase in slope of the bed coalescer. Thus, pressure drops of $200 \mathrm{~Pa}, 400$ $\mathrm{Pa}, 600 \mathrm{~Pa}, 700 \mathrm{~Pa}, 1100 \mathrm{~Pa}$, and $1200 \mathrm{~Pa}$ were observed for $\alpha=0^{\circ}, 5^{\circ}, 15^{\circ}, 30^{\circ}, 45^{\circ}$, and $60^{\circ}$, respectively.

For smaller slopes, the pressure drop occurs mainly due to acceleration and friction forces, whereas with the increase of the inclination there is a greater influence of the hydrostatic forces (Kokal \& Stanislav, 1989).
Considering the data presented in Figure 4 and according to Sokolovic et al. (2007), an equipment that leads to the lowest possible pressure drop will favor a greater degree of separation, and prevent the formation of preferential paths along the porous bed. Thus, the setting that would most favor this cenario in accordance with the simulations is the horizontal $\left(\alpha=0^{\circ}\right)$ as well.

\section{CONCLUSIONS}

The study of oil concentration zones shows that, with the increase of the angle of inclination, there is a decrease of the oil concentration in the upper part of the bed, being the most satisfactory result for null angulation with the horizontal.

The streamlines showed that there is an increase in recirculation of the oily mixture with inclination increase, impairing the stability of the oil-water emulsion and making it difficult to separate the oil. It is also noted that the pressure drop tends to increase with the slope due to the increased turbulence and the presence of hydrostatic pressure of the fluid.

Thus, horizontally, there is a better separation in oil-water system due to the longer residence time; a lower oil dispersion, evidenced by the lower number of recirculation zones; and, consequently, a lower pressure drop. Further, such a configuration favors a controlled oil withdrawal by implementing a specific output at the upper end.

\section{NOMENCLATURE}

Latin letters:

$\begin{array}{llr}D & \text { Pipe diameter } & \mathrm{cm} \\ K & \begin{array}{l}\text { Porous media } \\ \text { permeability }\end{array} & \mathrm{L}^{2} \\ P & \text { Pressure } & \mathrm{ML}^{-1} \mathrm{~T}^{2} \\ R e & \text { Reynolds number } & - \\ S_{M} & \begin{array}{l}\text { Sum of external } \\ \text { momentum forces }\end{array} & \mathrm{ML}^{-2} \mathrm{~T}^{-2} \\ & \text { Coalescence time } & \mathrm{T} \\ t_{i j} & \text { Velocity vector } & \mathrm{LT}^{-1}\end{array}$


Greek letters:

\begin{tabular}{|c|c|c|}
\hline$\alpha$ & $\begin{array}{l}\text { Angle with the horizontal } \\
\text { plane }\end{array}$ & 一 \\
\hline$\Gamma$ & Domains porosity & 一 \\
\hline$\theta_{i j}^{B}$ & $\begin{array}{l}\text { Buoyancy driven collision } \\
\text { rate }\end{array}$ & $\mathrm{L}^{3} \mathrm{~T}$ \\
\hline$\theta_{i j}^{S}$ & $\begin{array}{l}\text { Collision rate due to } \\
\text { laminar shear }\end{array}$ & $\mathrm{L}^{3} \mathrm{~T}$ \\
\hline$\theta_{i j}^{T}$ & $\begin{array}{l}\text { Collision rate due to } \\
\text { turbulence }\end{array}$ & $\mathrm{L}^{3} \mathrm{~T}$ \\
\hline$\mu_{e}$ & Effective viscosity & $\mathrm{ML}^{-1} \mathrm{~T}^{-1}$ \\
\hline$P$ & Density & $M / L^{3}$ \\
\hline$\tau$ & Stress tensor & $\mathrm{MT}^{-2}$ \\
\hline$\tau_{i j}$ & Bubble contact time & $\mathrm{T}$ \\
\hline
\end{tabular}

Symbols:

$\begin{array}{ll}\nabla \cdot & \text { Divergence operator } \\ \nabla & \text { Gradient operator } \\ \otimes & \text { Tensor product }\end{array}$

\section{REFERENCES}

Albuquerque, R. D. A.; Marinho, J. L. G.; Oliveira, L. M. T. M. Estudo numérico da variação da concentração de óleo na água de produção de petróleo em um leito coalescedor. Proceedings XI Congresso de Engenharia, Ciência e Tecnologia. Brazil, 2018. (In Portuguese)

Amini, S.; Mowla, D.; Mahdi, G.; Esmaeilzade, F. Mathematical Modelling of a hydrocyclone for the down-hole oil-water separation (DOWS). Chemical Engineering Research and Design, v. 98, p. 21862195, 2012.

https://doi.org/10.1016/j.cherd.2012.05.007

ANSYS INC, ANSYS CFX-Pre Theory Guide, Release 13.0, 2010.
Ariaratnam, G. D.; Roth, N. J. Produced water management - The challenges faced. In: Proceedings Offshore Technology Conference, 22, March 2016, Houston, Texas. https://doi.org/10.4043/26402-MS

Arowoshola, L.; Cope, G.; David, V.; Gassson, C.; González-Machón, C.; Kelleher, M.; Lang, H.; Uzelac, J. Produced water market. Opportunities in the oil, shale and gas sectors in North America. Global Water Intelligence Publication, v. 12, 2011.

BRAZIL, Brazilian Government, Resolution: CONAMA n 430 (2011). (In Portuguese)

Ferreira, D. N.; Marinho, J. L. G.; Oliveira, L. M. T. M. Coalescer bed modeling to mixture oil/water: Treatment using ANSYS CFX. Brazilian Journal of Petroleum and Gas, v. 12, p. 135-147, 2018. https://doi.org/10.5419/bjpg2018-0013

Hirsch, C. Numerical Computation of Internal and External Flows: Fundamentals of Computational Fluid Dynamics. V. 1. N. 2. Elsevier, 2007.

https://doi.org/10.1016/B978-075066594-0/50039-4

Igunnu, E. T.; Pfennig, A.; Chen, G. Z. Produced water treatment technologies. International Journal of Low-Carbon Technologies, v. 9, p. 157177, 2014. https://doi.org/10.1093/ijlct/cts049

Ishii, M., Zuber, N. Drag coefficient and relative velocity in bubbly, droplet or particulate flows. AIChE Journal, v. 25, p. 843-855, 1979. https://doi.org/10.1002/aic.690250513

Kokal, S. L.; Stanislav, J. F. An experimental study of two-phase flow in slightly inclined pipesII. Liquid holdup and pressure drop. Chemical Engineering Science, v. 44, p. 681-693, 1989. https://doi.org/10.1016/0009-2509(89)85043-2

Kulkarni, P. S.; Patel, S. U.; Chase, G. G. Layered hydrophilic/hydrophobic fiber media for water-inoil coalescence. Separation and Purification Technology, v. 85, p.115-164, 2012. https://doi.org/10.1016/i.seppur.2011.10.004

Magiera, R., Blass, E. Separation of liquid-liquid dispersions by flow through fibre beds. Filtration and Separation, v. 34(4), p. 369-376, 1997. https://doi.org/10.1016/S0015-1882(97)90566-8 
Maiti, S.; Mishra, I. M.; Bhatthacharya, S. D.; Joshi, J. K. Removal of oil from oil-in-water emulsion using a packed bed of commercial resin. Colloids and Surfaces A: Physicochemical and Engineering Aspects, v. 398, p. 291-298, 2011. https://doi.org/10.1016/i.colsurfa.2011.07.041

Prince, M. J.; Blanch, H. W. Bubble coalescence and break-up in air-sparged bubble columns. AIChE Journal, v. 36, p. 1485-1499, 1990.

https://doi.org/10.1002/aic.690361004

Sherony, D. F.; Kintner, R. C. Coalescence of an Emulsion on Fibrous Bed: Part I. Theory. The Canadian Journal of Chemical Engineering, v.49(3), p. 314-320, 1971.

https://doi.org/10.1002/cjce.5450490304

Sokolovic, R. M. S.; Vulic, T. J.; Sokolovic, S. M. Effect of bed length on steady-state coalescence of oil-in-water emulsion. Separation and Purification Technology, v. 56, p. 79-84, 2007. https://doi.org/10.1016/i.seppur.2007.01.028

Sokolovic, R. M. S.; Sokolovic, D. S.; Sevic, S. Oily water treatment using a new steady-state fiberbed coalescer. Journal of Hazardous Materials, v. 162, p. 410-415, 2009.

https://doi.org/10.1016/i.jhazmat.2008.05.054
Sokolovic, R. M. S.; Sokolovic, D. S.; Govedarica, D. D. Liquid-liquid separation using steady-state bed coalescer. Hemijska Industrija, v. 70, n. 4, p. 367-381, 2016. https://doi.org/10.2298/HEMIND150309041S

Sokolovic, R. M. S.; Vulic, T. J.; Sokolovic, S. M.; Neducin, R. P. M. Effect of fibrous bed permeability on steady-state coalescence. Industrial \& Engineering Chemistry Research, v. 42, p. 30983102, 2003. https://doi.org/10.1021/ie020361i

Speth, H.; Pfennig, A.; Chatterjee, M.; Franken, $H$. Coalescence of secondary dispersions in fiber beds. Separation and Purification Technology, v. 29, p. 113-119, 2002. https://doi.org/10.1016/S13835866(02)00067-9

Vigneaux, P.; Chenais, P.; Hulin, J. Liquid- liquid flows in an inclined pipe. American Institute of Chemical Engineers, v. 34, p. 781-789, 1988. https://doi.org/10.1002/aic.690340508 